\title{
Loss of excitation of synchronous generator
}

\author{
Vladimír Krištof, ${ }^{*}$ Marián Mešter ${ }^{* *}$
}

\begin{abstract}
This paper presents results of study of loss-of-excitation phenomena simulations. Loss of excitation is a very common fault in synchronous machine operating and can be caused by short circuit of the field winding, unexpected field breaker open or loss-of-excitation relay mal-operation. According to the statistic [1], the generator failure due to loss-of-excitation accounts for $69 \%$ of all generator failures. There has been concern over possible incorrect operation of the relay when operating the generator in the under-excited region, during stable transient swings and during major system disturbances. This article can serve as inputs for system operators in preparation of operation area or protection relaying area.

K e y w ord s: loss of excitation, excitation system, synchronous generator, stability
\end{abstract}

\section{Introduction}

The loss of synchronism (stability) of synchronous generator and the subsequent transition to asynchronous operation is a very serious and unfavorable operating condition. It occurs if the machine is not able to transmit the electrical power $\left(P_{e}\right)$ corresponding to supplied mechanical power $\left(P_{m}\right)$. This could be caused by the following reasons:

- loss of excitation of synchronous generator (significant decrease of internal electromotive force),

- weakening of the transmission grid (eg line outages),

- increasing of the transmitted power (threat for static stability),

- etc.

Asynchronous operation of synchronous generator is analyzed $e g$ in [2]. This article deals with the loss of excitation of synchronous generator.

\section{Excitation systems of synchronous machines}

The essential function of excitation system is to supply direct current for the power of synchronous machine excitation winding. Furthermore, it has several protection and control functions. The excitation system consists of two relatively independent components - excitation regulator (automatic voltage regulator) and the exciter itself [3]. The exciter power makes up generally $0.2-0.8 \%$ of the generator power. The exciter voltage generally does not exceed $1 \mathrm{kV}$ so that its winding does not need additional insulation [2].

Basically there are static and rotating exciters. In rotating exciters, the excitation current is obtained from direct current generators (eventually alternative current generators equipped with rectifiers). Since direct current sources do not provide the necessary power, they are connected into cascade. This is however followed by increasing of equivalent exciter time constant (and thus worsening of exciter dynamics).

Basic components of static excitation systems are thyristor rectifiers, controlled with excitation regulator by means of thyristor ignition impulse circuits. This can be performed in two ways via the transformer, namely either from an independent source (so called independent excitation) or directly from the generator (so called dependent excitation). The main benefit of static excitation systems is the speed with which the excitation voltage responds to the change of regulator voltage.

The excitation systems of synchronous machines are subject of following requirements:

- keep the generator in a condition when it is possible by (long) lines to transmit the power close to the limit line power (ie enable the generator operation in the area of so called artificial stability [4]),

- ensure sufficient dynamic stability reserve and damping of generator power swings after failure,

- maintain stability during change of properties of electric lines or grid to which the generator is connected,

- easily and reliably measure the parameters according to which regulation occurs,

- high operating reliability.

An integral part of the excitation system is apart from the exciter itself also the excitation regulator. The primary task of the excitation regulator is to maintain the required voltage on generator terminals. In addition, the excitation regulator generally fulfills most of the following supplementary functions $[3,5]$ :

- limiter of rotor and stator current: protects generator before stator or rotor circuit overloading,

- under-excitation limit control: main aim is to prevent machine de-excitation (under-excitation) to the degree

\footnotetext{
* Power System Management s.r.o., Ondavská 5, 04001 Košice, Slovakia, kristof.vladimir@gmail.com ** Vchodoslovenská distribučná, a.s., Mlynská 31, 04001 Košice, Slovakia, marian.mester@gmail.com
} 


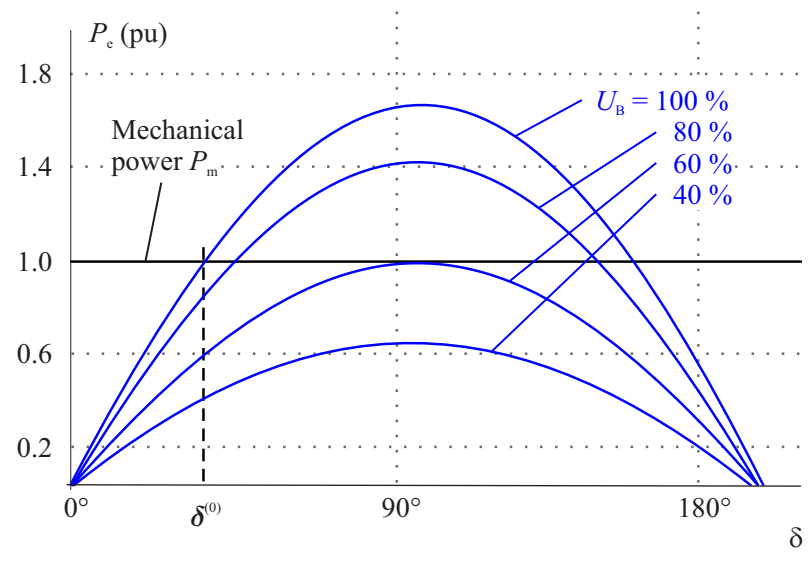

Fig. 1. Power - angle characteristic for individual values of excitation voltage $U_{B}$

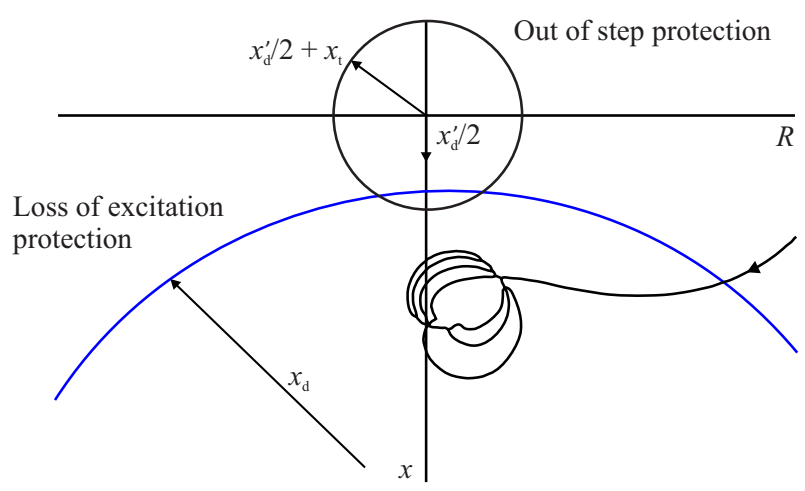

Fig. 2. Measured trajectory in the impedance plane during loss of excitation

where threat of its static stability arises, stator winding terminals warm up, etc,

- power system stabilizer: dampens electromechanical swings that originate as result of commutations in the grid,

- secondary regulator of reactive power: maintains reactive power on desired value.

From the above presented facts it is obvious that excitation systems are important components of both the generator as well as the electricity grid. Therefore, it is desirable that they provide the highest possible operating reliability. The outages or failures in excitation systems can have very unfavorable operating consequences.

\section{Loss of excitation protection}

Loss of excitation of synchronous generator can be caused by several factors, such as power supply outage, exciter damage or short circuit in the excitation winding. Regardless of the reason the loss of excitation represents a high risk with regard to synchronous generator damage. In addition, outage of synchronous generator with high unit power represents a significant risk for the stability of electricity grid. During loss of excitation the current in excitation winding decreases (exponentially). Proportionally also the internal electromotive force and the electromagnetic relation between the stator and rotor decrease. This is reflected in gradual decrease of reactive power on generator terminals. When the under-excitation limit is achieved, the loss of synchronism occurs (the relation between the stator and rotor is already very week at this time). This whole process is similar to loss of static stability of synchronous machine. The development of loss of synchronism after loss of excitation can simply be explained by power characteristics. For the electric power supplied with generator to grid under stabilized conditions the following applies

$$
P_{e}=\frac{E_{G} E_{S}}{X} \sin \delta
$$

where $E_{G}$ is internal voltage of generator, $E_{S}$ - grid voltage, $X$ - transmission reactance and $\delta$ is rotor angle (angle between $E_{G}$ and $E_{S}$ ).

The intersection between the turbine mechanical power $\left(P_{m}\right)$ and power curve $(P-\delta)$ defines the operating rotor angle (sometimes so called load angle). Decreasing internal voltage of generator results in decreased power curve (Fig. 1). As the power curve decreases the rotor angle increases and gets close to the limit operating point $\left(\delta_{\text {crit }}=90^{\circ}\right)$. At this point the electric power supplied by generator reaches its maximum level (for respective operating conditions). The following subsequent decrease of the power curve as result of loss of excitation will cause that generator will no longer be able to transmit the electric power corresponding to the mechanical power of turbine. The imbalance (excessive mechanical power of turbine) will be reflected in the generator rotor speeding up. Generator speeding up will be then reflected in the decreasing turbine power (corresponding to turbine regulator statics). Under certain circumstances, when the decrease of the excitation voltage is successfully stopped by machine operator, the new balanced operating point (with worse operating conditions) will be achieved. The resulting generator rotations are determined by turbine regulator statics and grid "toughness" (in synchronous operation of extensive grid the rotations generally do not change, whereas in island mode operation the frequency/rotations deviation can reach up to $5 \%$ before the machine is disconnected from the grid).

The loss of excitation is a transient phenomenon of medium speed with the time interface of several seconds (3 to 8 seconds according to [6]). The loss of excitation represents a threat mainly from the following reasons [7]:

- stator overloading as result of significant supply of reactive power from the grid (0.4 to 1.9-multiple of $S_{n}$ ), - warming up of rotor winding influenced by induced currents,

- extensive swings of active power, which are typical for asynchronous operation.

The loss of excitation can have adverse effect not only on the generator itself, but also on the whole grid and adjacent generators - mainly if they are connected to 

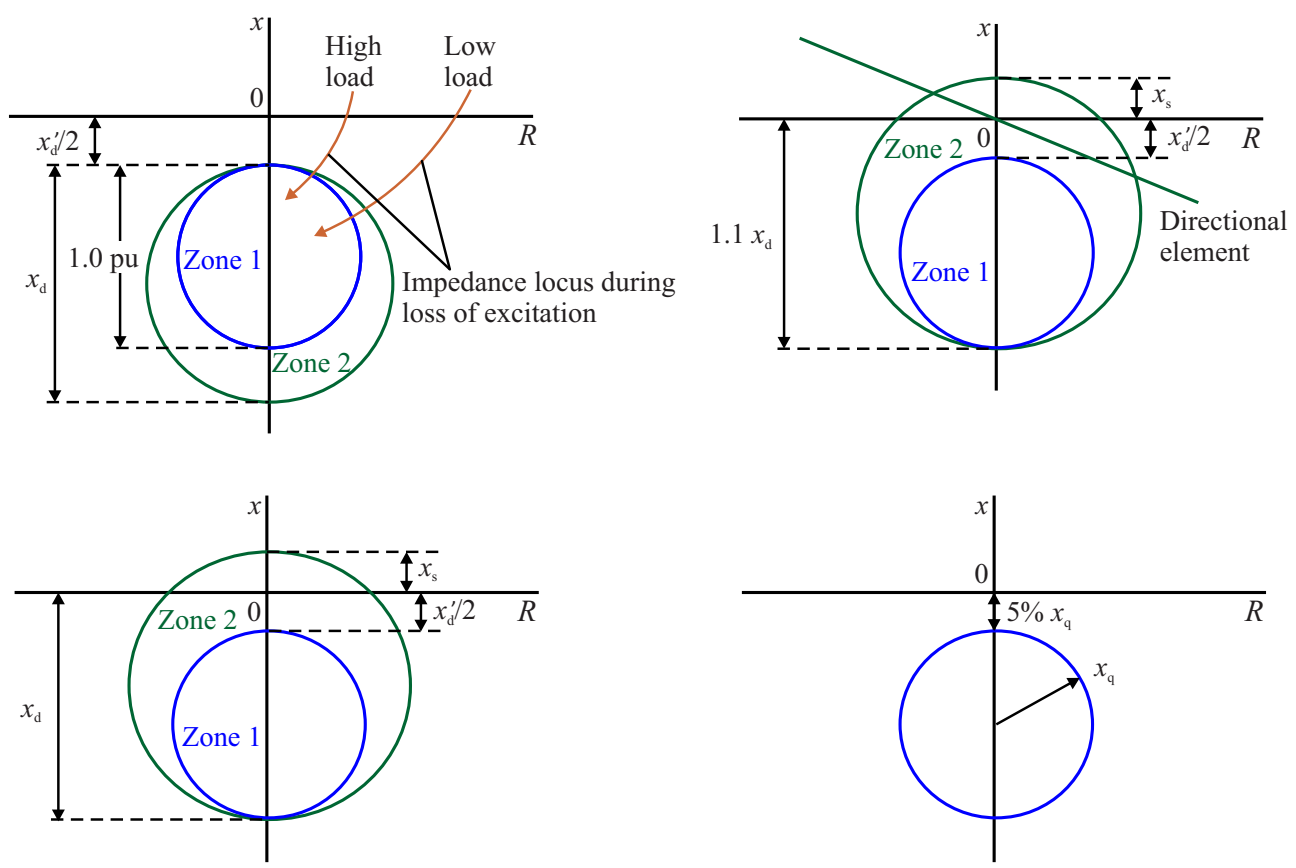

Fig. 3. Impedance patterns of loss of excitation protection

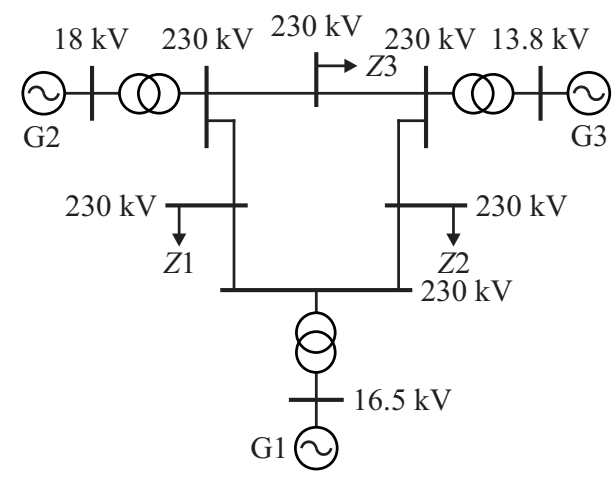

Fig. 4. 9-node test grid IEEE

common point with the generator that lost excitation (i.e. generators in one power plant). As was presented above in the text, if generator lost excitation it changes into significant consumer of reactive power. If this generator is not shut down, the adjacent generators start increasing the production of reactive power up to the limit when their limiters of rotor and stator currents act. The effect of loss of excitation on adjacent generators is analyzed in more details in [8].

If not even the grid can cope with increased supply of reactive power, it can cause overloading and subsequent the transmission lines outages in cascades. Significant decrease of voltage in individual nodes of the grid and the resultant threat of voltage collapse could have another adverse effect.

Operators of the transmission grids shall for reasons of planning the operation, development or maintenance of safe and reliable supplies of electric energy perform extensive calculations. Calculations of dynamic stability of grid after loss of excitation of important generators within the grid should also be considered. Since dynamic simulations are time consuming, use of so called screening technique appears to be more suitable [6]. This technique applies classic calculation of power system load flow with the aim to determine critical machines, or nodes in the grid based on so called grid screens where loss of excitation of generator could have adverse effects. Following the identification of critical nodes, simulations on dynamic models for specific examples shall be performed for purposes of detailed analysis, proposal of protection settings during loss of excitation or other necessary safety measures.

\section{Loss of excitation protection}

Loss of excitation protection is the so called impedance type of protection. Their first installations reach back to 50 -ties of the last century. The impedance principle is with good results used also nowadays, since it has high ability to detect loss of excitation and at the same time is very reliable. However, there is an area of generator operation when this type of protection can function improperly. These are the cases when generator operated in under excited condition, during stable transient power swings in the grid and during significant system outages with frequency drop [8].

Example of measured impedance on generator terminals is shown on Fig. 2. It can be seen that the impedance trajectory seen by the protection on machine terminals crosses the characteristic of loss of excitation protection and enters into it. This excites the impulse for protection 


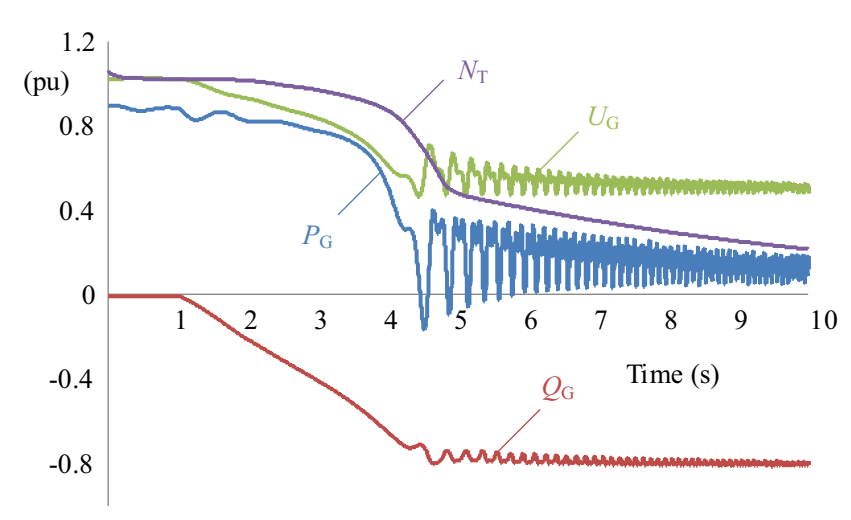

Fig. 5. Courses of values of generator No. 2 during loss of excitation

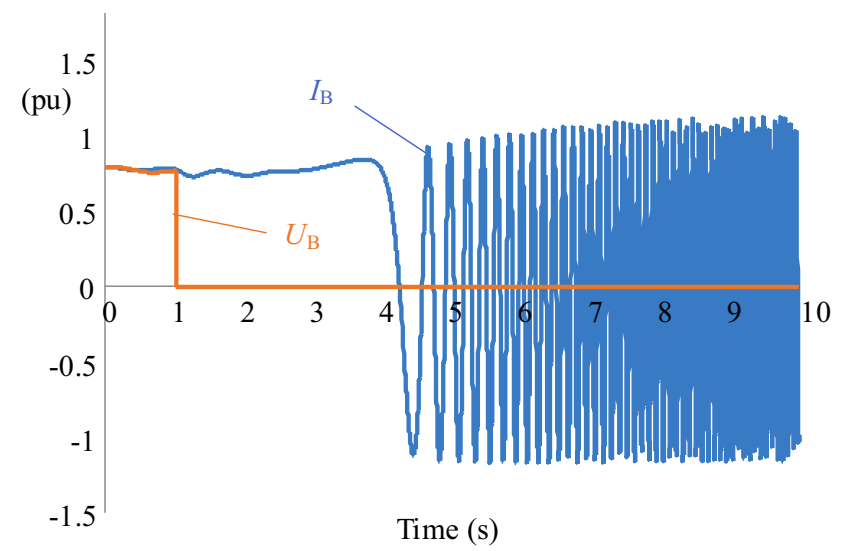

Fig. 6. Courses of values of generator No. 2 during loss of excitation

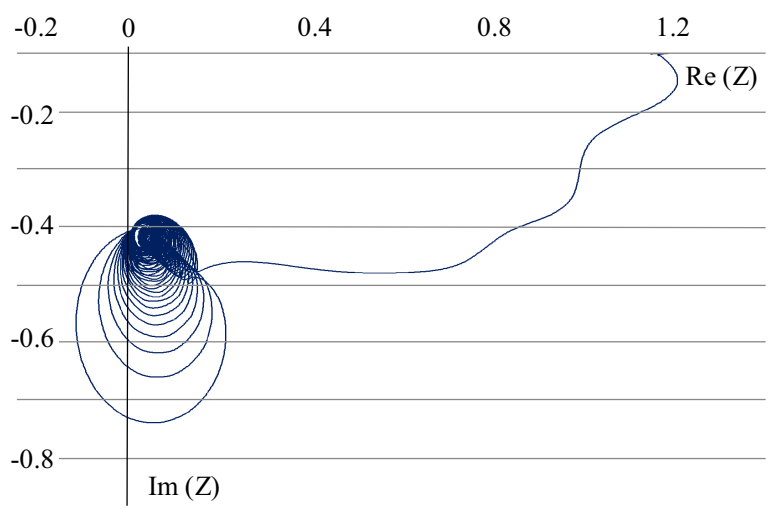

Fig. 7. Impedance measured with protection during loss of excitation

impulse component and as long as the impedance stays in operation zone of protection for some specified period, the protection issues command to shut down the synchronous generator. This shut down command is issued with time delay of 1 to 2 seconds in order to prevent undesirable protection operation during some swing effects in the grid.

Typical operation characteristics of loss of excitation protection are presented in Fig. 3. The characteristics shown on Fig. 2a and $\mathrm{b}$ are defined by the IEEE standard [9]. The characteristic (b) has an extra directional element built in in order to prevent undesirable opera- tion of protection during some swing effects in the grid or close faults (i.e. during short circuit on terminals of block transformer). The characteristic (c) is taken over from IEEE, it is modified and used in China [10]. Finally, the characteristic (d) is an example of older type of protection D21 used also in our power system [2].

\section{Simulation on dynamic model}

The loss of excitation of synchronous generator and the operation of protection during loss of excitation can be demonstrated on the following example. For simulation purposes the network simulator MODES (see [11]) was used. As the test grid the 9-node IEEE grid taken from [12] was used.

In the reference article [10] similar simulations of the loss of excitation were performed using different methods. For simulation purposes the following two were used:

- short circuit in excitation winding $\left(U_{b}=0\right)$,

- disconnection of excitation winding $\left(I_{b}=0\right)$.

In MODES the loss of excitation according to first method is simulated by intervention in the scenario. By the command Par2 the exciter parameters change in time. By this intervention $U_{b}=0$ is forced to the exciter set.

Second method $\left(I_{b}=0\right)$ can be simulated by forcing $U_{n}=0$ to the exciter set and at the same time by change of the generator parameter $T d 0^{\prime} \rightarrow 0$. This will cause a stepwise increase of excitation winding resistance $R_{\mathrm{BUD}} \rightarrow \infty$. This method is obvious from the following PARK formulas that are used in network simulator MODES to describe the complete generator model ("PARK" model)

$$
\begin{aligned}
& T_{d 0}^{\prime} * E_{q}^{\prime \circ}=U_{B}+\left(X_{d}-X_{d}^{\prime}\right) * I_{d}-E_{q}^{\prime}, \\
& T_{q 0}^{\prime} * E_{d}^{\circ \circ}=-\left(X_{q}-X_{q}^{\prime}\right) * I_{q}-E_{d}^{\prime}, \\
& T_{d 0}^{\prime \prime} * E_{q}^{\prime \prime \circ}=E_{q}^{\prime}+\left(X_{d}^{\prime}-X_{d}^{\prime \prime}\right) * I_{d}-E_{q}^{\prime \prime}, \\
& T_{q 0}^{\prime \prime} * E_{d}^{\prime \prime \circ}=E_{d}^{\prime}-\left(X_{q}^{\prime}-X_{q}^{\prime \prime}\right) * I_{q}-E_{d}^{\prime \prime},
\end{aligned}
$$

where $E_{q}^{\prime}, E_{d}^{\prime}, E_{q}^{\prime \prime}, E_{d}^{\prime \prime}$ are phasors projections of electromotive forces into axis $d$ and $q, I_{d}, I_{q}$ are stator currents projections, $U_{B}$ is excitation voltage, $T_{d 0}^{\prime}, T_{d 0}^{\prime \prime}$, $T_{q 0}^{\prime \prime}$ are time constants of synchronous machine in no load condition, $X_{d}, X_{d}^{\prime}, X_{d}^{\prime \prime}$ are synchronous, transient and subtransient reactance in direct axis, $X_{q}, X_{q}^{\prime}$ are synchronous and transient reactance in quadrature axis.

It is obvious that the first formula is the most decisive for excitation modelling. The time constant $T_{d 0}^{\prime}$ is determined by the ratio $L / R$. From this it is obvious that the disconnection of excitation winding will simulate a condition when $T_{d 0}^{\prime} \rightarrow 0$ or $R_{\mathrm{BUD}} \rightarrow \infty$. As base values the nominal values of stator voltage, current and excitation voltage in no load condition were selected. Under this assumption the electromotive force behind synchronous 


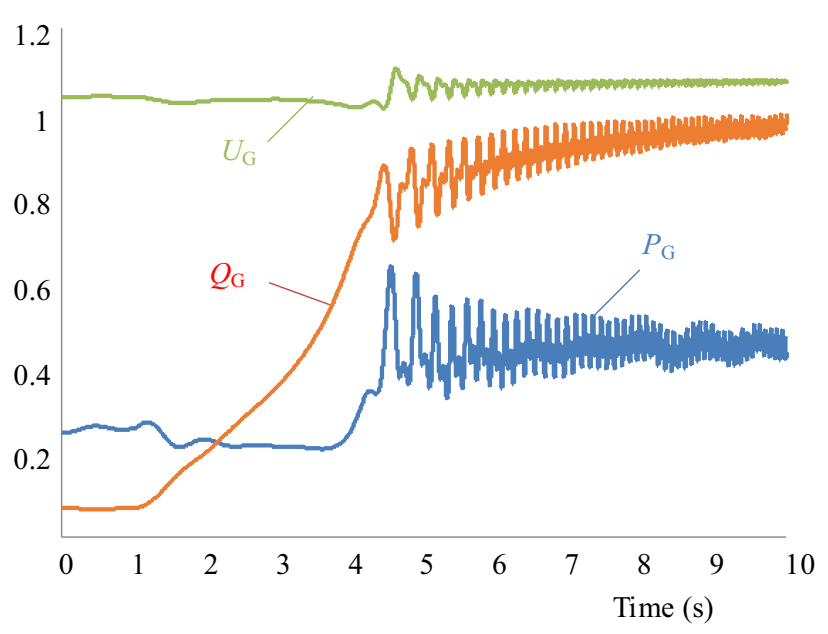

Fig. 8. Courses of values of generator No. 1 during loss of excitation

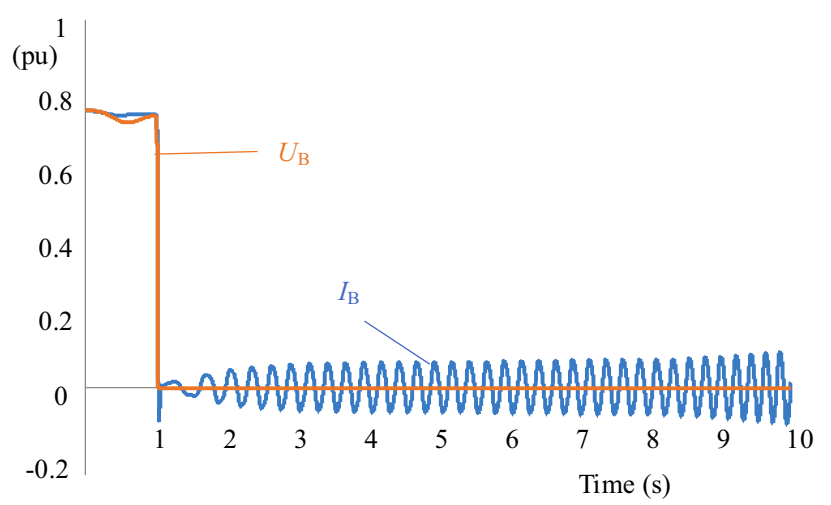

Fig. 10. Courses of values of generator No. 2 during loss of excitation

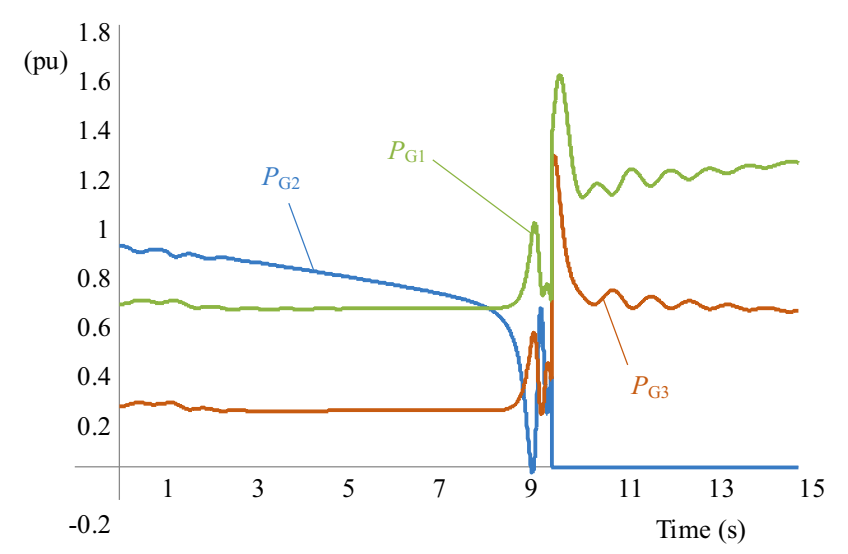

Fig. 12. Courses of active powers of generators

reactance $E_{q}$ equals to excitation current $I_{b}$. It applies the following

$$
E_{q}=I_{B}=E_{q}^{\prime}-\left(X_{d}-X_{d}^{\prime}\right) * I_{d} .
$$

Let's assume that on generator No. 2 at the time of $1 \mathrm{~s}$ there occurs the loss of excitation as result of short circuit in excitation winding. The courses of relevant values are presented in Figs. 5 and 6 , where $P_{G}$ stands for active power of generator, $Q_{G}$ is reactive power of generator, $U_{G}$ is voltage on generator terminals, $N_{T}$ is turbine

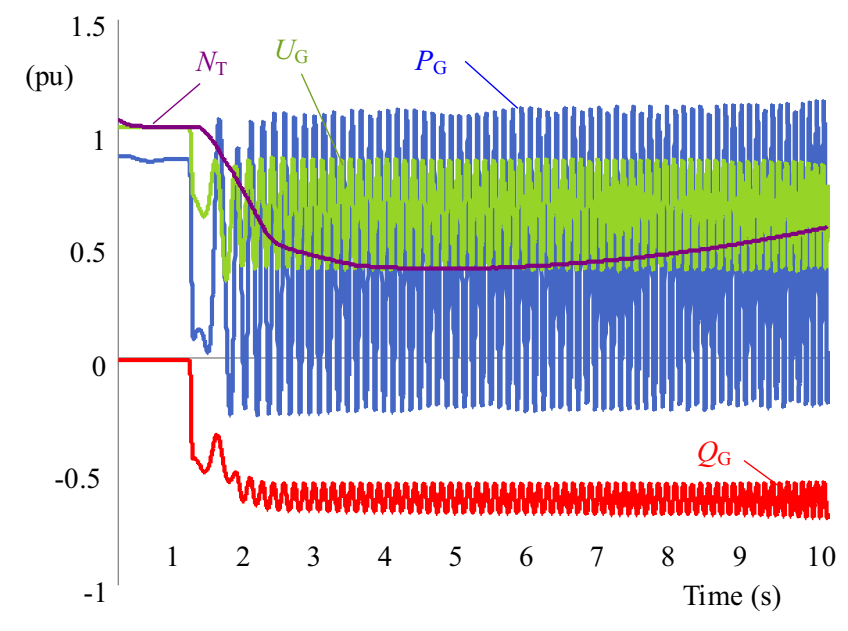

Fig. 9. Courses of values of generator No. 2 during loss of excitation

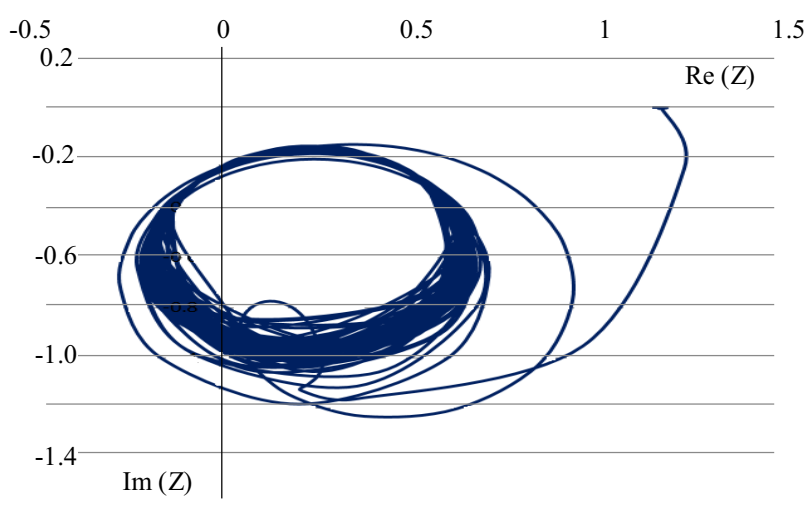

Fig. 11. Impedance measured with protection during loss of excitation

power, $I_{\mathrm{BUD}}$ is excitation current and $U_{\mathrm{BUD}}$ is excitation voltage.

From the courses presented in Figs. 5 and 6 it is obvious that after loss of excitation the machine starts to take reactive power from the grid and at the time just after the $4^{\text {th }}$ second the machine loses synchronism. This is obvious from the saw-tooth courses of values (powers, voltage) that are typical for asynchronous operation. The impedance measured with protection in Fig. 7 responds well with its quality to the impedance course in the reference article [10].

Figure 8 shows the courses of values of generator No. 1 . From the presented courses it is obvious that generator No.1 responded to failure of generator No. 2 by increasing the production of active power (influence of rotations regulation) and also reactive power. However, since generator No. 2 was not disconnected from the grid it also caused swings of remaining two machines operating in the grid.

Figure 9 shows the courses of relevant values for generator No. 2 for the scenario when the excitation winding was disconnected (ie the second method $\left(I_{b}=0\right)$ ).

When comparing the courses of values during loss of excitation it is obvious that the second method (i.e. dis- 
connection of excitation winding) is less favorable and excitation decreases faster and subsequently generator loses synchronism. The following figure shows the patterns of active powers of generators G1 to G3 for the case that protection acts during loss of excitation at the time $t=9$ $\mathrm{s}$. It is clear that the protection shuts down generator G2 on time and this has significant importance from the perspective of maintaining the stability of remaining generators operating in the grid.

\section{Salient pole (hydrogenerator) vs cylindrical (turbogenerator)}

The publication [13] explains that the hydrogenerator should be immediately shut down after loss of excitation. The protection acts on signal, switch, de-excitation and quick release of the turbine. However, the protection will not shut down the turbogenerator immediately. It acts on automatics during loss of excitation (ANSI 40). The automatics acts on turbine regulator and decreases the generator power. Since it is heated up it enables the operation of generator in above synchronous rotations for some time. This is how operators or excitation regulator get time and can take an early action to eliminate the cause (if it is possible) and thus prevent unnecessary shut down of generator. If it is not possible to eliminate the cause until the specified period, the automatics will shut down the generator.

We will try to analyze this situation in more detail. Hydroelectric generators are synchronous machines with salient poles where $x_{d} \neq x_{q}$. The generally applicable relation for calculation of electric active power supplied by generator into the grid, specified also above in this article, is simplified. Fully covered relation, described in per units, can be expressed as (in accordance with [14])

$$
p_{e}=\frac{u_{b} u_{S}}{x} \sin \delta+u_{s}^{2} \frac{x_{d}-x_{q}}{2 x_{d} x_{q}} \sin 2 \delta .
$$

This relation consists of two elements. First is the torque, or power of synchronous machine that is proportional to excitation voltage (first part of equation). Second is so called reluctance power (second part) that is usually neglected in calculations. However, if it is considered and $u_{b}=0$, ie we assume the loss of excitation occurred, we determine there is reluctance power on the machine shaft. With detailed analysis of asynchronous and synchronous machine in excited and non-excited condition we can conclude the following:

1) Asynchronous machine: has squirrel cage rotor with regular arrangement. During operation with asynchronous rotations neither swings nor power changes occur during constant load.

2) Synchronous machine in excited condition: by increasing the power up to the stability limit only the internal machine angle (rotor angle) increases. Once this limit is crossed synchronism loss and mechanical shocks on the shaft and turbine occur. These shocks have slip frequency.

3) Synchronous machine in non-excited condition: its behavior is somewhere between the two previous examples. The machine continues to operate as asynchronous machine, ie with slip. It has obviously zero synchronous torque determined with the magnetic field of rotor. However, there still operates the already mentioned reluctance torque that is proportional to the difference of longitudinal and transverse reactance of the machine. During each slip the swing (shock) originates, the intensity of which is also dependent on the difference of longitudinal and transverse reactance. This means that the average torque and power on the shaft remain approximately equally big as at the time before loss of excitation. The machine supplies asynchronous power (similarly as asynchronous machine) in the grid. The immediate power and torque of the machine swing around this median at each slip by the value of reluctance power. If we consider the machine is turbogenerator, ie machine with cylindrical rotor, that has a very small difference between longitudinal and transverse reactance, the immediate value of power and torque of the machine will slightly swing. In case of hydroelectric generator, ie machine with salient poles, the swing will be apparent, since there is significant difference between the machine reactances.

From this analysis it is obvious that the hydroelectric generator shall be shut down as soon as possible after loss of excitation. Turbogenerator can operate with approved asynchronous operation for some time, as long as it is allowed by the manufacturer. However, the question is why to keep such machine in non-excited condition further in operation. This depends on several factors:

- operating method of the whole grid,

- importance of machine that lost excitation protection,

- will the outage of this machine be a threat for the grid stability?

- can the machine supplying lower power for some time improve the grid stability?

Basically, there are two viewpoints with respect to this issue. If the machine is shut down later, the grid stability will face a smaller threat, yet there will be higher risk of rotor overheating and machine damage. On the other hand, if the machine is shut down earlier, it will be better for the machine itself, yet with worse consequences for the grid stability. Practically, not even turbogenerators are allowed to operate in asynchronous operation for above stated reason in order not to cross the allowed warming of rotor parts or damper (amortisseur) windings. Generally, it is subject of agreement of the grid operator, generator operator and generator manufacturer whether such machine is disconnected from the grid immediately or asynchronous operation is allowed for some time. Finally, this time information should be provided by the manufacturer in type tests. 


\section{Conclusion}

Article deals with loss of excitation of synchronous generator. It describes physical nature of this phenomenon, protection devices against loss of excitation and also shows possibility of using of network simulator MODES for loss of excitation analysis.

The article emphasizes the need of this type of calculations in real operation of transmission systems because of the loss of synchronism (stability) of synchronous generator and the subsequent transition to asynchronous operation is a very serious and unfavorable operating condition. Loss of synchronism can damage faulted generator but also can cause problems with stability (angle, voltage) in power system. In last chapter article analyzes possibility of operation when generator loses synchronism. There are three type of machine operation analyzed. This analysis shows that in case of turbogenerator further operation of generator must be allowed by producer of machine and also by operator of transmission system. In case of hydrogenerator further operation is not allowed in any case.

\section{REFERENCES}

[1] Z. Shi, "Investigation on Generator Loss of Excitation Protection in Generator Protection Coordination", School of Electrical Engineering Royal, Institute of Technology, Stockholm, Sweden 2010, http://www.diva-portal.org/smash/get/diva2:610188/ fulltext01.pdf.

[2] K. Máslo and L. Haňka, "Analýza asynchrónního chodu generatoru", 5. mezinárodní konference CP\&HS 2002, Zlín, 2002, (in Czech).

[3] O. Hora, Regulační a budící systémy synchronních strojů, SNTL, Praha, 1985, (in Czech).

[4] F. Janíček, V. Chladný, A. Beláň and Ž. Eleschová, Digitálne ochrany $v$ elektrizačnej sústave. (Digital Protection in Power System), Vydavatel'stvo STU, Bratislava, 2004, (in Slovak).

[5] K. Máslo, "The General Purpose Network Simulator MODES", Proc. of the 4th Int. Workshop on El. Power System Control Centers, Rethymno, Greece, 1997.

[6] H. G. Darron, J. K. Koepfinger, J. R. Mather and P. A. Pusche "The Influence of Generator Loss of Excitation on Bulk Power
System Reliability", IEEE Trans Power Apparatus and Systems, vol. 94, no. 5, 1473-1481, 1975.

[7] J. Tlustý, J. Kyncl, L. Musil, J. Špetlik, J. Švec, P. Hamouz, M. Müller and Z. Müller, Monitorování, řízení a chránění elektrizačních soustav, České vysoké učení technické v Praze, Praha, 2011, (in Czech).

[8] J. Berdy, "Loss of Excitation Protection for Modern Synchronous Generator", IEEE Trans Power Apparatus and Systems, vol. 94, no. 5, 1457-1463, 1975.

[9] IEEE Std.C37.102 - 2006: IEEE Guide for AC Generator protection. IEEE Power System Society 2006.

10] Y. Siwang, W. Weijian, L. Ling, G. Ling and Q. Arui, "Discussion on Setting Calculation of Loss of Excitation Protection for Large Turbogenerator", International Conference on Electrical Machines and Systems (ICEMS), Incheon, 2010.

11] P. M. Anderson and A. A. Fouad, Power System Control and Stability, 1977, Iowa State Press University.

[12] V. Chladný, Digitálne ochrany v ES, Technická Univerzita Košice, 2007, (in Slovak).

13] P. Dohnálek, Ochrany pro průmysl a energetiku, 1991, (in Czech).

Received 18 November 2016

Vladimír Krištof was born on July 1985 in Košice, Slovakia. He received the MSc and $\mathrm{PhD}$ in Power System Engineering from Technical University in Košice, Faculty of Electrical Engineering and Informatics, Department of Electric Power Engineering. He is currently Power system calculation specialist in company Power System Management, Ltd. He was a member of scientific teams on two scientific projects. $\mathrm{He}$ is also author or co-author of 2 university books and more than 20 scientific and technical papers. His work is focused in the field of power system stability, short-circuit currents, power quality and wide area monitoring system.

Marián Mešter born in 1973, received the MSc and PhD in Power Engineering from Technical University in Košice. Since 1998 he teaches at Technical University in Košice, Faculty of Electrical Engineering and Informatics, Department of Electric Power Engineering. He is currently Head of Distribution System Operation Section in distribution company Východoslovenská distribučná, a.s. He is also author or coauthor of 5 books and more than 70 scientific and technical papers. He is focused on research in the field of stability of power system, short-circuit current and digital relays. 